\author{
CARLOS BIZARRO MORAIS \\ Universidade Católica Portuguesa \\ camorais@ucp.pt
}

\title{
Da presença de Schelling na estética ontológica de Mikel Dufrenne
}

\section{Schelling's presence in Mikel Dufrenne's ontological aesthetics}

\begin{abstract}
RESUMO: Problematizaremos a influência da ideia de Natureza de Schelling no pensamento estético de Dufrenne. Uma influência estruturante mas controversa, dada a sua implicação na perceção-limite que ela auspicia: de indiferenciação, em que sujeito e objeto mutuamente se aderem e se constituem, numa correlação a priori. Ora, esta prodigalidade da Natureza manifesta-se ao propiciar a referida simbiose, e sobretudo ao tornar presente, deixando-o jorrar, um sentido bruto/selvagem, incipiente mas explícito para apontar uma direção de causalidade poiética, gerando a possibilidade de uma interpretação ontológico-metafísica. Torna-se assim tangível uma matriz instauradora, aproximável pela dimensão estético-artística da existência. Daí o seu interesse crítico.
\end{abstract}

PALAVRAS-CHAVE: SCHELLING; MIKEL DUFRENNE; NATUREZA; ESTÉTICA ONTOLÓGICA; EXPERIENCIA ESTÉTICA

\begin{abstract}
This paper intends to discuss how Schelling's notion of Nature influences Dufrenne's aesthetic thought. A key yet controversial influence, as it impacts the perception-limit it heralds: of oneness, whereupon subject and object intertwine in an a priori correlation.

Such prodigality of Nature is evident both in this symbiosis and especially in the overflowing emergence of a brute/wild undercurrent - embryonic yet overt - as a path towards a poietic causality, prone to ontological and metaphysical interpretation. A pursuable matrix thus arises, which can be tapped by the aesthetic-artistic scope of existence. Hence its critical interest.
\end{abstract}

KEYWORDS: SCHELLING; MIKEL DUFRENNE; NATURE; ONTOLOGICAL AESTHETICS; AESTHETIC EXPERIENCE 


\section{Arte e Filosofia no encalço da Natureza}

$\mathrm{M}$ ikel Dufrenne ocupou-Se, desde o início do seu percurso, com a problemática relação entre a arte e a filosofia. Num dos seus primeiros trabalhos, intitulado "Philosophie et littérature", dá-nos conta da novidade que constitui o profícuo relacionamento entre a filosofia e a arte, aqui exemplificada pela literatura.

O filósofo e o artista, com os seus respetivos mundos, surgem comprometidos com as nobres causas universais. Pensamentos e obras de arte, nas suas diferenças, comunicam e convergem pelo mais profundo de si. Trata-se, mais propriamente, de uma forma superior de conluio, de conivência, em que a filosofia se abre às formas de expressão artística, poética e literária, chegando a inspirar-se nelas. Os discursos filosóficos, argumenta Dufrenne, «dizem à sua maneira, às vezes muito próxima da poesia, o que dizem as artes, convidam-nos ao mesmo pensamento» (Dufrenne, 1976: 594). Isto só é possível porque se reconhece que a dimensão evocativa da arte internaliza o poder representacional dos conceitos filosóficos e constitui mesmo um desafio para a própria filosofia. Neste sentido, aquilo que a arte revela e descobre é exatamente aquilo de que a filosofia busca aproximar-se: «a arte faz viver aquilo que a filosofia se esforça por pensar: o imediato da presença» (Dufrenne, 1986: 19). Ambas procuram, acima de tudo, o originário. No horizonte desta confluência, Dufrenne revisita Schelling, na edificação de um todo orgânico-quiasmático, intrínseca às duas atividades.

O auge desta afinidade surge na interação da arte com a metafísica, no poder que a arte possui de colocar o pensamento na rota da metafísica. Não a metafísica entendida à maneira clássica ou tradicional, mas uma metafísica que surge quando a filosofia recupera a Natureza. Como afirma Dufrenne: «A filosofia reabilita a metafísica logo que ela se propõe como filosofia da Natureza» (Dufrenne, 1990: 1005). A poesia assume aí a tarefa fundamental a nível da expressão, na medida em que está toda ela empapada, mergulhada na fonte, na Natureza: a poesia restitui as palavras e o mundo à Natureza, as suas grandes imagens apresentam um extraordinário poder simbolizador do dinamismo cósmico, são evocações do originário naturante. Nesta linha, afirma Dufrenne: «Desde que uma reflexividade excessiva não a paralise, [a poesia] joga com as grandes imagens: a terra, o azul dos céus, a árvore, a fonte, a onda, as estações... Estas imagens, nas quais o homem experimenta a sua presença ao mundo, sugerem também o surgimento irrepressível do mundo: evocam o fundo, o originário. Dão a sentir - a pressentir - o que não pode ser articulado e dominado pelo discurso: aquilo que Merleau-Ponty chama o ser bruto, o além - que é também o aquém - daquilo que a "física" pode dizer quando circunscreve e define o real» (ibid.). 
Se a poesia é a primeira linguagem da Natureza, não admira que o filósofo solicite a companhia do poeta para dar o salto fundamental: do homem à Natureza, do fundamento ao fundo, da linguagem do homem à fala originária na qual se anuncia a si mesma. Em síntese, a poesia não é, propriamente, uma metafísica, contudo "pode despertar o sentimento de uma metafísica» (ibid.). Mostra o surgimento do ser ao aparecer, o movimento do invisível ao visível, a «poïésis do naturante», o "estilhaçamento do originário». A poesia adquire um acréscimo de sentido porque se deixa inspirar pelo Sagrado da Natureza: o poeta fala para deixar falar a Natureza, logo a linguagem que aparece é a fala primordial da Natureza.

O que pretendemos sublinhar é que este processo se molda pelo uso fulgurante da intuição estética, muito próximo daquela que o próprio Schelling defendeu, capaz de revelar o ser: "A intuição estética torna-se em Schelling o órgão e o método supremo da filosofia: ela revela o ser», afirma Michel Ribon (1997: 226). Por aqui vemos que, para Dufrenne, a arte, nomeadamente a poesia, não é apenas necessária para revelar a manifestação do divino na natureza, mas ela é também, numa certa perspetiva próxima do panteísmo schellingiano «o magnífico prolongamento, no homem, do trabalho artístico da natureza e da sua incessante evolução» (ibid, 228).

\section{A Natureza COMO lugar DE "Verdadeira GÉNESE”}

Não se trata de averiguar, neste momento, o grau de interiorização com que Mikel Dufrenne terá (ou não) acatado este programa da superiorização da arte em relação à filosofia. O que para nós é mais significativo, é que se entreabriu à reflexão estética da arte a porta de acesso a uma atmosfera ontológica, que apresenta a particularidade de resistir à atração do dualismo. É pela ideia de Natureza que o caminho se realiza.

Vejamos sucintamente esta questão do dualismo. Dufrenne declara tê-lo superado, descobrindo em Schelling uma nova instância, capaz de dar conta da harmonia radical que existe entre a consciência e o mundo, o a priori subjetivo e o a priori objetivo. Essa instância identifica-se com a já referida Natureza: «acontece que percorri este caminho e que encontrei uma certa ideia de Natureza à qual aderi fortemente» (Dufrenne, 1981: 12). Esta ideia deixa antever a possibilidade de uma mais credível exposição da "verdadeira génese», algo que é determinante no seu pensamento.

É, então, em Schelling que Dufrenne encontra a orientação primordial para a sua filosofia da Natureza. Ao modo de Schelling, conceptualiza-a como Grund, força indomável e inqualificável de existir, um Fundo que é Fundamento e ao mesmo tempo insondável, sem fundo, abismo ou Abgrund, ser "bruto e originário" que reside no fundo de toda a coisa (cf. Dufrenne, 1973: 210): a Natureza é «a plenitude do real, a opacidade massiva do fundo» (Dufrenne 
\& Formaggio, 1981b: 46), ser invisível donde emerge misteriosamente todo o sensível, o nosso corpo "senciente", donde tudo vem e ao qual tudo regressa.

Mas uma Natureza que integra, também, traços de uma sombria negatividade que fazem sobressair quão essa Natureza está carenciada de um foco de luminosidade, que só a subjetividade do ser humano lhe pode proporcionar. Uma Natureza que espera o humano, e este, logo que chega, imediatamente a escuta, imitando-a no seu poiein. Sem o humano não se efetua o acesso ao sentido e à verdade: «não há verdade senão na descoberta de um sentido que aclara e transfigura o real, e graças à aptidão de uma subjetividade para captar este sentido» (Dufrenne, 1967: 648). Sem essa intervenção iluminadora, a Natureza jamais poderia devir mundo.

A Natureza entrelaça, assim, simultaneamente a realidade e a possibilidade, e é dessa união que emerge o dinamismo genesíaco que traz à existência o para-si desde a profundidade do em-si (cf. Dufrenne, 1973: 214). Por isso, esta possibilidade, «potência do ato», tem a sua raiz na realidade, não se trata de uma possibilidade lógica, mas de um possível «que significa a plenitude do real, a sua autoridade e a sua eficiência» (ibid.). Ora, a Natureza desenvolve o seu poder atualizando os seus possíveis (cf. ibid, 221), segundo uma necessidade interior que lhe é própria; por isso, ela jamais é sinónimo de uma inércia de debilitamento, de estéril contingência ou determinismo cego de uma realidade «que se ofereça como matéria-prima a um homem naturante» (Dufrenne \& Formaggio, 1981b: 31).

Ao afirmarmos que a Natureza é propriamente o real, queremos dizer que ela é um «fundo inextinguível, enquanto princípio do devir. Não é mais concebida como o em-si inerte da matéria, mas é a potência do possível» (ibid, 44). Ela «é uma reserva, uma fonte animada pela 'força silenciosa dos possíveis'» (Dufrenne, 1973, 215). A Natureza permite-nos, pois, articular o conceito de real com o de possível, ou melhor, sondar o real como campo de possíveis.

Ora, não é exatamente isso que acontece na relação com a obra de arte? $\mathrm{Na}$ obra de arte distende-se um mundo - não como parte do mundo objetivo ou como mero ponto de vista sobre ele - mas como terreno de um ainda-não que convida o espectador a abrir-se-lhe. E esta dimensão do "ainda-não" faz luz sobre a questão do possível, enquanto condição radical da própria realidade que traz em si o sujeito e o objeto, o homem e o mundo. Um possível que ilumina o real porque o antecipa: na obra - diz Dufrenne - «o real é vivido como campo de possíveis. E mais, aparece através destes possíveis puros que são os a priori» (Dufrenne, 1967: 649). Para compreender esta Natureza como naturante, como produtora de possíveis e geradora de história, é necessário restituir-lhe a temporalidade. Dufrenne explicita que «é a ideia schellinguiana de Potência que parece exprimi-la melhor» (1973: 221). "Potência de um possível” é a designação 
que significa «a via pela qual a Natureza é naturante» (Dufrenne \& Formaggio, 1981b: 45). Ora, esta é a ideia estruturante de Natureza em Schelling.

\section{A NATUREZA APETRECHADA DE SUbJetividAdE}

Com esta realidade limite que é a Natureza-fundo aproximamo-nos de uma clara construção metafísica em que aquela instância, sem deixar de ser essencialmente ante-histórica, é já temporal, e portanto capaz de um devir, de um dinamismo de aparecer: «a vocação do ser é a de aparecer, a sua potência é em última análise potência de desvelamento» (Dufrenne, 1973: 219).

É importante salientar que não se confere jamais ao homem nem à consciência e ao sujeito transcendental um papel soberanamente constituinte da realidade e do sentido. Nem mesmo se pode antropomorfizar a Natureza ou conceber o fundo em função do fundamento; é a Natureza, que sendo potência, possui este poder, «só o fundo pode produzir aquilo com o qual se instaura o fundamento» (ibid, 218). Por outros termos, é a Natureza que deve inspirar o homem, a sua perceção, a sua razão, e não o homem como modelo ou arquétipo da Natureza.

Não é difícil encontrar nesta ideia claros sinais de uma metafísica finalista, como o sublinha Ruyer; tanto mais que a Natureza como fundo é a "potência" que produz aquilo com o qual se instaura o fundamento (cf. Ruyer, 1963: 199 200). Poder-se-ia duvidar deste finalismo da Natureza, por estar conotada como "potência", e na medida em que evoca assim um movimento de "trans/ descendência" mais do que de "trans/ascendência", como acontece com a metafísica de Schelling. Porém, a identificação da energia desta "potência” com a força "negentrópica" ("négentropie") que prevalece sobre o acaso no universo, e sobretudo no fenómeno da vida, desfaz qualquer reserva.

Estamos, assim, claramente, diante de uma Natureza que, por ser Natura naturans, é em si mesma arauto e portadora de subjetividade, algo que, na verdade, Schelling já tinha tematizado, mas da qual Dufrenne retira as devidas consequências. Vale a pena estabelecer os dados fundamentais deste tópico.

Sabemos que na filosofia da natureza de Schelling se entrecruzam duas linhas de influência, como bem explica Rivera de Rosales (2002: 60): por um lado, a filosofia da subjetividade transcendental, de Kant e de Fichte; e uma outra linha de pensamento, que entronca numa filosofia do Absoluto, onde pontifica Espinosa e a sua natura naturans. De um ao outro constrói Schelling o processo de transformação do Eu fichteano, num Eu que é «de facto um absoluto, todas as coisas, um hen kai pan». Doravante está bem identificado o programa de Schelling: «unir a substância de Espinosa com a subjetividade transcendental de Fichte»; ou seja, que «a substância se torne sujeito» (ibid). 
A noção dufrenneana de Natureza torna-se ainda mais clara, quando se reconhece este processo schellinguiano de incremento da subjetividade da $\mathrm{Na}$ tura naturans. Ora é verdade que Schelling «dá um passo mais além, e afirma a subjetividade latente e constitutiva de toda a natureza» (ibid, 61), orientação condensada na sua afirmação lapidar: " "O filósofo da natureza trata a natureza como o filósofo transcendental trata o Eu"» (citado in Rosales, 2002: 61) ${ }^{1}$. Assim, essa subjetividade "pré-reflexiva" ou "atividade ideal" é a Natura naturans, "princípio ativo, criador e ordenador dos objetos do mundo» (Rosales, 2002: 61), que se vai operacionalizando em produtos cada vez mais complexos e organizados, como o corpo humano, e neste, na atividade livre, reflexiva, racional. A intuição pura ou imaginação criadora conduz-nos à união originária de espírito e matéria presente de modo mais lídimo na organização dos seres vivos.

Ora, o que é surpreendente em Schelling - e que constitui um filão para Dufrenne - é que ele reivindica para a natureza orgânica toda essa subjetividade, com o seu poder de imaginar, pré-reflexivo, anterior aos procedimentos da conceptualização, indissociavelmente unida à objetividade. Afirma Schelling: «"No produto natural está ainda unido o que no atuar livre se separou (...) O homem é um eterno fragmento (...) Assim pois, o fenómeno completo da liberdade e da necessidade, unidas no mundo externo, só a natureza orgânica mo oferece"» (citado in Rosales, 2002: 62) ${ }^{2}$. É por isso que, tão espontaneamente, se desencadeia em nós a ideia de que estamos originariamente unidos a essa natureza - como repete Dufrenne: trata-se de uma relação de autêntica conaturalidade.

Este quesito de uma subjetividade constituinte da Natura Naturans é deveras significativo, na medida em que resguarda do risco de uma leitura materialista. Esta tenderia a explicar a subjetividade pela objetividade da matéria ou da natura naturata; pelo contrário, Schelling «faz surgir o sujeito reflexivo desde a natureza considerada como sujeito-objeto ou natura naturans, desde a subjetividade da própria natureza» (Rosales, 2002: 63). Este tópico é de grande relevo, atendendo ao debate bastante acalorado em redor de um pretenso materialismo do próprio Dufrenne.

Ora, é diretamente do poiein desta Natura naturans que Dufrenne recolhe a caracterização e a atribuição dos fatores subjetivos e objetivos da sua noção de um $A$ priori que estrutura o mundo, o humano, a criação artística, os distintos momentos da vivência, e finalmente o Real. Por isso, não surpreende que a fenomenologia dufrenniana adquira cada vez mais o perfil de uma ontologia poética, muito próxima «dos abismos metafísicos de Espinosa e de Schelling», como se lhe referiu Bernhard Waldenfels (1997: 124).

[1] . Schelling, $S W$ [Edição do filho de Schelling] III, 12 nota = AA I/7, 275.

[2] . Schelling, Sistema [Sistema do Idealismo Transcendental], SW III, 608. 
É este o principal efeito da inspiração schellinguiana de Dufrenne. Se este permanecesse apenas no registo do A priori, significaria continuar limitado ao criticismo de Kant. Ao progredir para a noção de Natureza, sobretudo em Le Poétique, Dufrenne abre para a linhagem de Schelling, para o pensamento «da totalidade e da continuidade», segundo a interpretação de Jean-François Lyotard (1996: 48).

Por isso não temos dúvida de que a reinscrição da fenomenologia da experiência estética na versão de uma ontologia da Natureza opera agora uma metamorfose decisiva, reafirmando-se sob a forma de uma «metafísica, ou filosofia primeira da presença». Ela implica a inversão da onto-teologia negativa numa onto-fenomenologia "poeticamente fundada», assente numa "renovada fundação do sentido ou da essência do poético na Natureza naturante, tal como se prolonga e atua no mundo e na arte» (Formaggio, 1981: 7).

\section{NATUREZa E METAFÍsica [TRANSCENDÊNCIA]}

Será legítimo, então, falarmos de uma perspetiva aberta à transcendência?

A recorrente utilização de conceitos que albergam conotações "religiosas", como Presença, Fala, Voz, Apelo, Acolhimento, Inspiração, Luz pode indiciar a possibilidade de uma Realidade fundante, uma Natureza Primeira com o traço de Alguém, distinto e Causa da natureza e da subjetividade, aquém e além da relação sujeito-objeto, do a priori existencial e a priori cosmológico. Itinerário percorrido por muitos, para os quais o sentimento deste "Algo" incognoscível mas sempre presente como englobante, bem como a auscultação da sua Fala, abriram um campo onde puderam germinar respostas diversificadas a uma singular forma de transcendência. Ora, também neste aspeto nos parece que Dufrenne arrisca algo, sob as implicações do pensamento de Schelling. É o que se depreende da opinião de Jean-Dominique Robert: «Um Merleau-Ponty, um Dufrenne, um Piguet [...] tendem a remontar, de uma maneira ou de outra, a um Tertium Quid» (Robert, 1982: 335 e 336).

Que este movimento de ascensão e simultaneamente descendente denuncia uma ambiência teológica, como uma ascese espiritual, é algo que não passou despercebido à atenta reflexão de Ricoeur. Concretamente, que a solução possa já não prescindir de uma doutrina da criação e de uma Alteridade Outra! «Vêse facilmente - afirma Ricoeur - que é necessário subir da linguagem a uma origem que não é o homem, dar o 'salto' do fundamento humano ao fundo original; [...] é necessário atribuir à Natureza o desejo de se revelar, de aparecer, de se dizer: finalmente, é necessário atribuir-lhe algo como uma tendência à expressividade. Mas se a Natureza "deseja o homem falante", se o verbo lhe é co-extensivo, co-originário, a Natureza será ainda a "impensável potência do fundo"?» (Ricoeur, 1966: 116). 
Aponta-se, então para um Princípio de unidade. Mas de que natureza? À primeira vista poder-se-ia tomar a opção pela natureza como equivalente à adesão a um monismo dito "materialista", uma "matéria" capaz de conter em si todos os possíveis, as obras e suas belezas. Mas Dufrenne sabe que isso seria trair o pensamento de Schelling; sabe que não se pode hipostasiar como um absoluto em si, a menos que a própria matéria se transmute noutra coisa.

Não sendo matéria, será uma "Natureza"-Espírito? Monismo que se transmuta da matéria para o Espírito?

Segundo J. Dominique Robert, Dufrenne terá partilhado a conceção do princípio como um "neutro" ao qual se lhe tornou necessária uma determinação ulterior. Nesta linha, a Natureza é «um Neutro, ontologicamente, senão temporalmente, anterior à distinção natureza-espírito». Em seguida, na sequência da influência de Espinosa e Schelling, meteu o Espírito na Natureza, e por isso «a Natureza pode falar» (Robert, 1982: 338-9), dando lugar a uma natureza-artista, percebida como lugar de manifestação do divino, como um credo estético e místico. A Natureza surge, então, dotada de uma atividade que é um Todo... é um Logos que manifesta a sua própria essência nos espetáculos dramatúrgicos que ela nos dá de si própria. Potência infinita, que é capaz de continuamente restabelecer os equilíbrios. E a contemplação desta Natureza surge, para o espetador, como um processo de refontalização espiritual, capaz de nos mostrar a falácia dos dualismos.

Ora, perguntar-se-á, quando o Espírito se imanentiza ao próprio Universo a Fala terá condições de concretização? Poderá ser enviada por Alguém a alguém? Poderá a Natureza comunicar com o espectador ou com o artista? E poderá ela ouvir as respostas?

Se a Natureza é o fundo, o fundo significa origem-causa absoluta, que dá ser e sentido. E convém recordar que o sentimento estético tange este originário e este sentido arquetípico, com toda a carga de questionamento que eles comportam. É por isso que Dufrenne fala de uma outra fonte da ideia de Deus, aquela que nos vem, precisamente, pelo sentimento que capta a necessidade e a grandeza presente nessa singularíssima Natureza (cf. 1973: 207). Ora, Dufrenne dá especial atenção à dimensão pré-reflexiva da afetividade, no sentimento estético, bem como ao papel que desempenha na génese cognoscitiva. $\mathrm{O}$ sentimento estético traz à luz um horizonte fundativo originário, que poderá ser chamado "pré-categorial» (cf. Franzini, 1997: 160).

Alicerçado este edifício que é pensamento de Dufrenne, podemos dizer que nos impele a considerar o Fundo-Natureza como Princípio-Causa sob o ângulo de uma explícita dimensão metafísica. Registamos, a propósito, o esforço de Dufrenne, tateando a possibilidade de uma transcendência que toque a dimensão religiosa, se a religião for «o sentimento do fundo [...] sentido como 
a força que anima todas as coisas e o vínculo que as une, como plenitude e reservatório». Sim, se Deus for «o nome dessa Natureza, [...], o ser-aí do ser, irresistível e injustificável. É para esse Deus que nos orientamos», afirma ele em Le Poétique (207). Mas, e esta é a questão final a que este trajeto nos conduziu: não serão estas marcas já suficientes para simbolizar a inquietação por uma realidade para lá da "indiferenciação" e da "neutralidade" da Natureza?

Pensar, com Espinosa e Schelling, a própria plenitude da Natura naturans, requer a possibilidade de um Princípio, cuja necessidade já foi antes referida, e que a arte inclina a que tenha Nome e seja Pessoal, porque ela é instituidora de verdadeiras relações. Além de que, a arte estimula a experiência dessa imaginação intuitiva e criadora - tão valorizada por Schelling e Coleridge - a atingir esse Princípio verdadeiramente transcendente. Por isso, podemos dizer que esta questão radical é ainda um "efeito de Schelling"!

\section{REFERÊNCIAS BIBLIOGRÁFICAS}

Dufrenne, M. 1967: Phénoménologie de l'expérience esthétique. T. I - «L'Objet esthétique»; T. II - «La Perception esthétique», Paris: PUF ( $2^{\mathrm{e}}$ édition).

Dufrenne, M. 1973: Le poétique. Paris: PUF, Paris (2e. édition, revue et augmentée, préc. de: «Pour une philosophie non théologique»).

DuFrenne, M. 1976 : L'Esthétique et les sciences de l'art in Tendances de la recherche dans les sciences sociales et humaines (Dir. M. Dufrenne). Paris: Mouton Éditeur, Unesco.

Dufrenne, M. 1981: L'inventaire des a priori. Recherche de l'originaire. Paris: Christian Bourgois Editeur.

Dufrenne, M. \& Formaggio, D. 1981b: Trattato di estetica. T. II: “Teoria”, Milano: Mondadori Editore.

Dufrenne, M. 1986: "Estetica e filosofia" in Aa.Vv., Statuto dell'estetica. Modena: Istituto Antonio Banfi di Reggio Emilia, pp. 12-20.

Dufrenne, M. 1990: "Métaphysique" in Etienne Souriau, Vocabulaire d'Esthétique. sous la dir. de Anne Souriau, Paris: PUF, pp. 1005.

Formaggio, D. 1981: "Mikel Dufrenne, la Natura e il senso del poetico. Saggio Introduttivo" in Mikel Dufrenne Il Senso del poetico. Edizioni 4 venti, Urbino, pp. 5-22.

FranZINI, E. 1997: Filosofia dei sentimenti. Milano: Mondadori.

Lyotard, J. F. 1996: "Langage et nature" in Revue d'Esthétique. 30, pp. 45-52.

Ribon, M. 1997: L'art et l'or du temps. Paris: Éd. Kimé.

Ricoeur, P. 1966: "Le Poétique" in Esprit. pp. 107-116

Robert, J-D. 1982: Essai d'approches contemporaines de Dieu en fonction des implications philosophiques du Beau. Paris: Beauchesne.

Rosales, J. 2002: "La reflexión transcendental sobre el cuerpo proprio. Kant, Fichte y Schelling” in J. Rivera de Rosales e M ${ }^{\mathrm{a}}$ del Carmen López Sáenz, (Coords), El cuerpo. Perspectivas filosóficas. Madrid: Universidad Nacional de Educación a Distancia, pp. 33-76. 
Ryber, B. 1963: [Étude critique] Le Poétique in Les Études Philosophiques. no 2, pp. 193-202.

Schelling, F. 1856-1861: Sämmtliche Werke. III, Edited by K. F. A. Schelling, Stuttgart/Augsburg

Waldenfels, B. 1997: De Husserl a Derrida. Introducción a la Fenomenología. Barcelona: Paidós. 